\title{
Use of a contoured bioresorbable plate with a hemostatic plug to control life-threatening bleeding from the superior sagittal sinus during hemispherotomy: technical note
}

\author{
Gerald F. Tuite, MD, ${ }^{1,3}$ Carolyn M. Carey, MD, ${ }^{1,3}$ William W. Nelson, MD, ${ }^{4}$ Scott J. Raffa, MD, ${ }^{1,3}$ and \\ S. Parrish Winesett, MD2,3 \\ Divisions of ${ }^{1}$ Pediatric Neurosurgery and ${ }^{2}$ Neurology, Neuroscience Institute, All Children's Hospital/Johns Hopkins Medicine, St. \\ Petersburg; ${ }^{3}$ Department of Neurosurgery and Brain Repair, Morsani College of Medicine, University of South Florida, Tampa; \\ and ${ }^{4}$ Division of Anesthesiology, Department of Surgery, All Children's Hospital/Johns Hopkins Medicine, St. Petersburg, Florida
}

\begin{abstract}
Profuse bleeding originating from an injured cerebral sinus can be a harrowing experience for any surgeon, particularly during an operation on a young child. Common surgical remedies include sinus ligation, primary repair, placement of a hemostatic plug, and patch or venous grafting that may require temporary stenting. In this paper the authors describe the use of a contoured bioresorbable plate to hold a hemostatic plug in place along a tear in the inferomedial portion of a relatively inaccessible part of the posterior segment of the superior sagittal sinus in an 11-kg infant undergoing hemispherotomy for epilepsy. This variation on previously described hemostatic techniques proved to be easy, effective, and ultimately lifesaving. Surgeons may find this technique useful in similar dire circumstances when previously described techniques are ineffective or impractical.
\end{abstract}

http://thejns.org/doi/abs/10.3171/2016.5.PEDS1633

KEY WORDS superior sagittal sinus; cerebral sinus; injury; repair; hemispherotomy; hemorrhage; technique

$\mathrm{U}$ NEXPECTED profuse bleeding from the superior sagittal sinus (SSS) during surgery can provoke anxiety for even the most seasoned neurosurgeon. Bleeding from far anterior sites can be definitively halted with SSS ligation with minimal risk of cerebral ischemia or hemorrhage. However, more posterior ligation of the SSS is known to carry a significant risk of brain injury due to stroke, hemorrhage, or raised intracranial pressure, thereby necessitating repair when possible. ${ }^{28,29,31,34}$

Repairing a copiously bleeding cerebral sinus can be trepidatious because temporary proximal and distal control of the vessel can be difficult to obtain. Surgeons are burdened with controlling potentially life-threatening hemorrhage while remaining acutely aware of the potential consequences of exsanguination or severe brain injury if the repair is not successful. ${ }^{28,33,35}$

Primary suture is the optimal repair solution, but this is

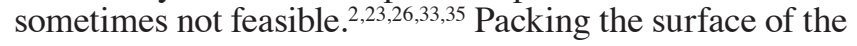

sinus with thrombogenic materials in combination with a fibrin sealant will often suffice when the tear is small and when direct pressure can be maintained on the hemostatic plug. ${ }^{2,411-14}$ For large tears, repair with adjacent dura, a separate autologous or allograft material, or even a vein graft can be performed, with or without the assistance of a temporary flow diversion stent. ${ }^{8,18,22,26,30,33}$ Emergency endovascular solutions may offer a viable alternative in some select cases in the ideal setting, but this method has not been widely reported. ${ }^{36}$

In this paper we report our solution to life-threatening intraoperative bleeding originating from a hole in the inferomedial side of the SSS during hemispherotomy in an $11-\mathrm{kg}$ infant. After considering and attempting many of the typical options, we were able to successfully stop the hemorrhage by fashioning a bioresorbable plate to hold packing material firmly against the medial surface of the SSS. 


\section{Case Report \\ Initial Operation}

This 11-kg, 11-month-old boy was selected for left periinsular hemispherotomy ${ }^{3,6,7,17,19,27,38}$ due to medically refractory epilepsy related to a large, left hemisphere, perinatal stroke (Fig. 1). The surgical approach proceeded without incident through a left frontotemporoparietal craniotomy that encompassed the insular area, with the medial margin of the craniotomy approximately $4 \mathrm{~cm}$ from the midline. A curvilinear dural opening was made, exposing an abnormal left hemisphere, consistent with imaging performed prior to surgery. The brain was noted to be bulging through the dural opening more than we would have expected in a child with brain atrophy (Fig. 2).

While the operating microscope was being draped, before any resection of the brain, brisk venous bleeding was noted to be originating from the subdural space. There was no clear cause for the bleeding. The opening had been uneventful, no brain resection had been performed, and the patient was not undergoing hyperventilation. Dural elevation and subdural exploration to locate the source of bleeding resulted in nearly uncontrollable bleeding and massive blood loss, leading to severe hypotension and a cardiac arrhythmia.

The resultant hypotension did reduce the bleeding enough to allow direct visualization of the bleeding site, which was determined to be an approximately 4-mm hole in the inferomedial side of the SSS. It appeared that a large cortical draining vein, possibly the vein of Trolard, had avulsed directly from the SSS along the middle one-third of the SSS. ${ }^{24}$

\section{Repair of the Bleeding}

Coagulation of the bleeding cortical vein and direct compression of the hole in the SSS with Surgicel (Johnson \& Johnson) followed by Floseal (Baxter), microfibrillar collagen (Avitene, CR Bard), and cottonoid patties stopped all bleeding, allowing the anesthesia team to transfuse packed red blood cells and fresh frozen plasma. Over the ensuing 30 minutes, direct pressure was maintained on the SSS while the child was stabilized. Brisk bleeding resumed every time the cotton patties were removed, regardless of the thickness of the hemostatic plugs, despite multiple attempts over subsequent hours.

Because the bleeding could be controlled with direct pressure, we chose to fashion a bioresorbable plate ( $\mathrm{Re}$ sorbX Mesh, KLS Martin LP) to hold the packing material in place over the defect in the SSS. The bioresorbable plate was contoured so it could be attached to the outer portion of the skull, bent $90^{\circ}$, and then shaped to maintain pressure on the packing material that was in place along the medial surface of the SSS (Fig. 3). To more securely hold the packing material in place, a long, thick, folded piece of dural substitute (Durepair, Medtronic) was placed between the hemostatic plug and the plate. We initially tried to fashion a titanium plate to hold the packing in place, but it fractured as it was bent excessively.

Temporal and occipital lobectomies were performed while the hemostatic plug was manually held in place by an assistant. All bleeding stopped after the bioresorbable

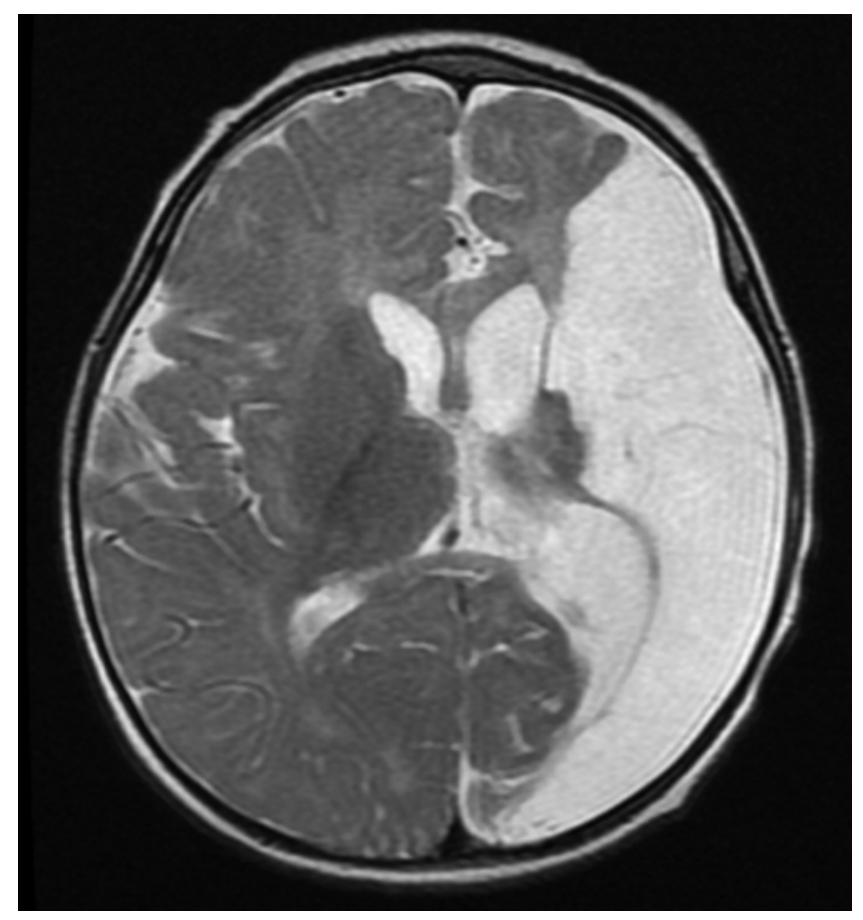

FIG. 1. Axial T2-weighted MR image of the infant prior to surgery, illustrating the extensive left hemispheric injury related to perinatal ischemia.

plate and packing material were in position. The dura was closed around the plate and the bone was replaced. The total operative time was 455 minutes exclusive of the anesthetic induction and preparation time. The total blood loss was $1400 \mathrm{ml}$ and the child received $1069 \mathrm{ml}$ (3 adult units, or 1.2 blood volumes) of packed red blood cells, $520 \mathrm{ml}$ of fresh frozen plasma, $40 \mathrm{ml}$ of platelets, $40 \mathrm{ml}$ of cryoprecipitate, as well as Factor VIIa (NovoSeven, Novo Nordisk) and vitamin $\mathrm{K}$. He was taken to the intensive care unit intubated, where he recovered.

\section{Postoperative Course}

The patient had an uneventful hospitalization for a child who had undergone a life-threatening operation. He was readmitted 4 weeks after surgery for Enterobacter cloacae meningitis, which required removal of the packing



FIG. 2. Photograph of hemisphere bulging through the dural opening before any resection began, which may have led to the venous avulsion from the SSS. Figure is available in color online only. 

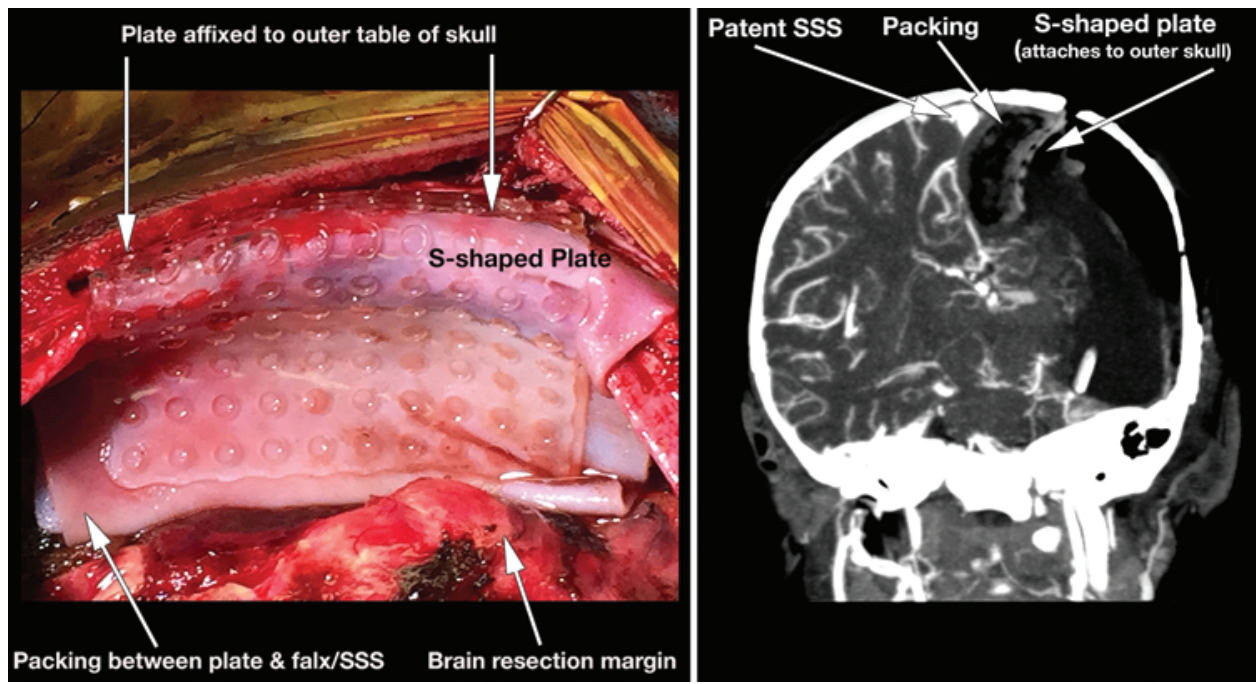

FIG. 3. Intraoperative photograph (left) taken just prior to closure, showing the bioresorbable plate contoured to hold packing material firmly against the falx and SSS. Coronal contrast-enhanced CT scan (right) performed 1 day after surgery, showing the bioresorbable plate holding Durepair and a hemostatic plug against a patent SSS. Figure is available in color online only.

material, the bioresorbable plate, and the bone flap. There was no bleeding from the SSS when the plate and packing material were removed. We realized there was a risk of bleeding associated with removal of the plate and packing, but we chose to return to surgery and accept that risk, without a lengthy trial of antibiotics, because the child had a serious infection with definite signs of sepsis. We believed that enough time had elapsed to allow sufficient healing of the sinus injury to allow attempted removal of the foreign body, which could have been contributing to the severity of the infection.

CT venography performed the day after the initial surgery showed a patent SSS, but venous imaging 1 month after surgery showed a partially occluded SSS (Fig. 4). The child was treated with enoxaparin (Lovenox, Sanofi) for 6 months. By 12 months, the posterior portion of the SSS showed recanalization but the anterior portion remained patent yet diminutive (Fig. 4).
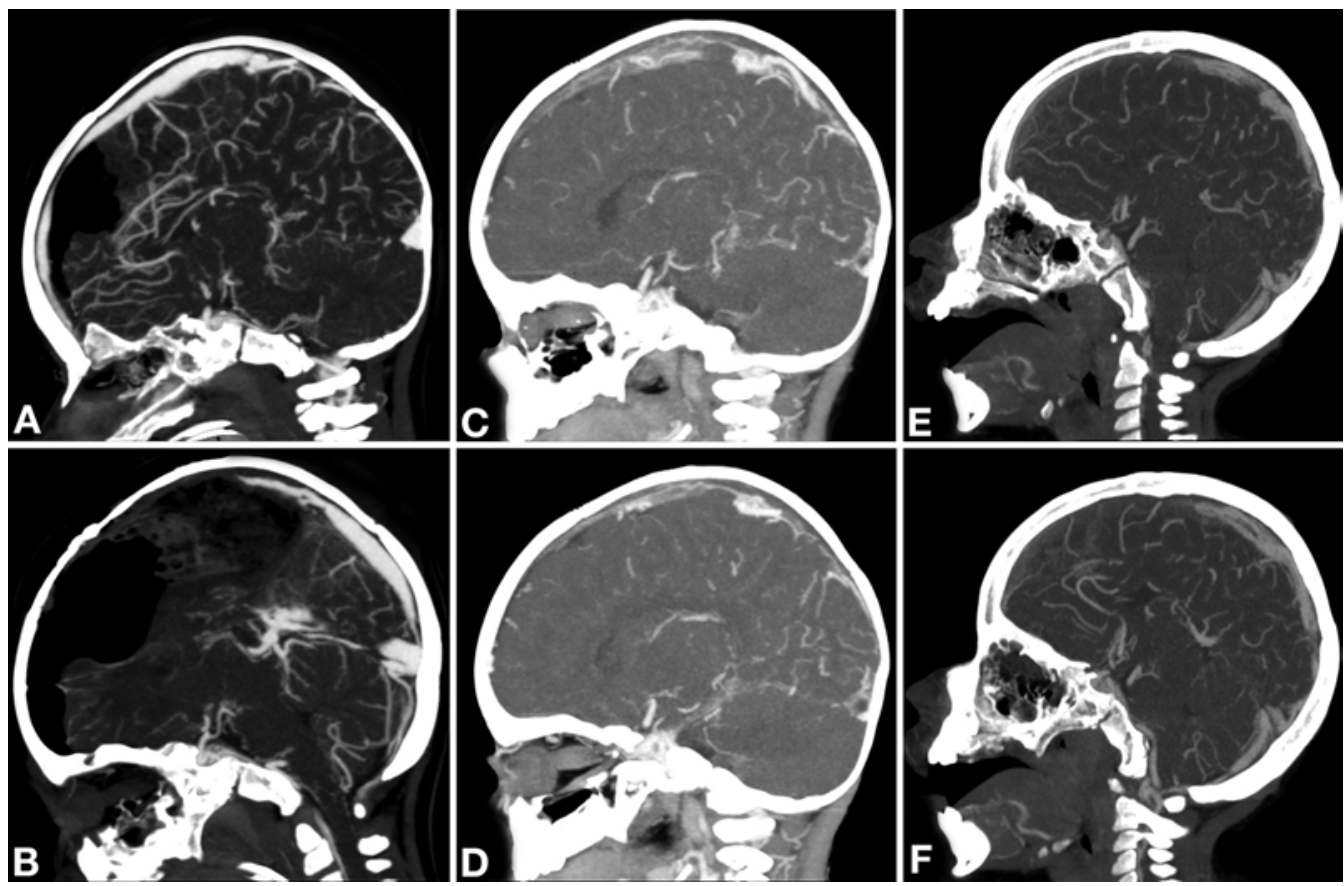

FIG. 4. CT venography performed the day after surgery ( $A$ and $B)$, and at 1 month ( $C$ and $D)$ and 1 year $(E$ and $F)$ after surgery. The anterior portion of the SSS is widely patent 1 day after surgery (A), occluded 1 month later (C), and partially recanalized at 1 year (E). Similarly, the posterior portion of the SSS is patent 1 day after surgery (B), mostly occluded at 1 month (D), and mostly patent $(F) 1$ year after surgery. 
No injury occurred on the contralateral hemisphere, and the boy's neurological examination did not change after surgery (Fig. 5). An extensive hematological evaluation also failed to show any evidence of coagulopathy. The child has remained seizure free since surgery 1 year ago, without any antiepileptic medications for 6 months.

\section{Discussion}

Hemispherectomy and its surgical variations have been successfully used for the control of medically refractory epilepsy since it was initially advocated by McKenzie more than 75 years ago. ${ }^{3,7,19,32,38}$ Excellent seizure control can be achieved in carefully selected patients, but early enthusiasm for the procedure was tempered by high complication rates, particularly related to acute and chronic bleeding. ${ }^{39}$ Refinements in surgical technique have reduced hemorrhagic complications, but recent reviews still point to a $0.9 \%-2 \%$ overall mortality rate after hemispherectomy. ${ }^{17,21,37}$

Seizure control with hemispherectomy can be particularly dramatic and gratifying in infants with some of the most severe forms of epilepsy, 1,3,5,8,10,15-17,20,21,25,27,37 but the risk of hemorrhage is greatest in babies with small total blood volumes and "immature brain and blood vessels that are fragile and vulnerable to bleeding." ${ }^{10}$ While intraoperative death due to bleeding is exceedingly uncommon with modern anesthetic and resuscitative techniques, coagulopathy is common and even cardiac arrest can occur during hemispherectomy in the modern age of surgery.1,10

The current case illustrates the fragility of the blood vessels in a young infant as well as the consequences of sudden, profuse hemorrhage in a baby with a small blood volume. Surgical trauma during the opening, brain manipulation, or the bulging of the brain through the dural opening (Fig. 2) may have led to the avulsion of a large draining vein from the SSS, which resulted in life-threatening hemorrhage, cardiac arrhythmia, and coagulopathy within a very short period of time. Based on this experience, we recommend efforts to maintain the normal position of the brain after dural opening. It is possible that a mild degree of hyperventilation and/or modifications of patient positioning (neck less turned, head up slightly) might have kept our patient's brain from bulging through the dural opening, which may have prevented a venous avulsion.
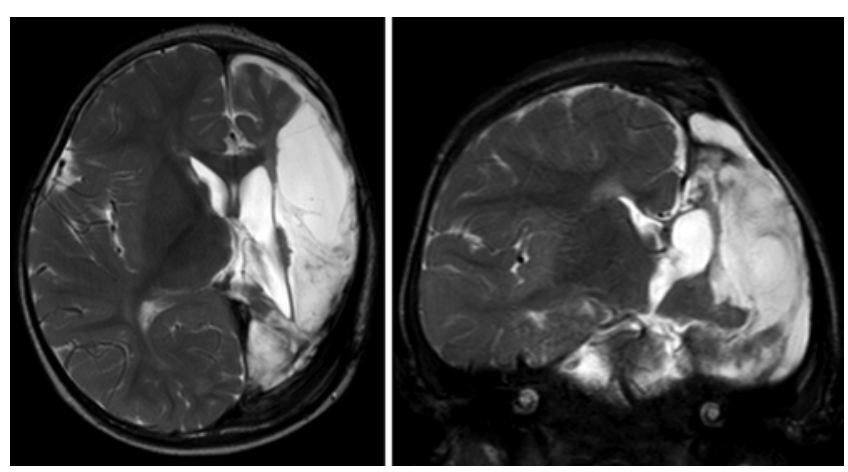

FIG. 5. Axial (left) and coronal (right) CT scans of the infant 1 year after surgery, demonstrating typical postoperative changes after temporal and occipital lobectomies with an unaffected contralateral hemisphere.
We chose to use a contoured bioresorbable plate to maintain pressure on the hemostatic material that was placed over the hole in the SSS only after the typical options to control bleeding were considered and many were attempted. We do not believe the utilization of a bioresorbable plate to maintain pressure on the hemostatic plug has been previously described, but the concept is a variation on techniques that have been described by other authors. ${ }^{2,4,11,12,14}$

Other authors have also reported excellent hemostatic efficacy with long-term sinus patency utilizing a fibrin sealant with a structural thrombogenic material. Most authors emphasize the importance of maintaining pressure on the plug, often utilizing a dural tenting hitch stitch to pull the dura firmly to the overlying bone..$^{2,4,11,12,14}$ Dural tenting was not technically feasible in our case because the SSS injury occurred along the inferomedial aspect of the SSS, in a location where a tenting dural stitch was not possible. As a substitute for a tenting suture, the bioresorbable plate proved easy and effective.

Before utilizing the bioresorbable plate to hold the packing material in place, other hemostatic techniques were considered and many were attempted. Complete ligation of the SSS was not considered prudent because of the risk of bilateral ischemia that might have resulted from ligation of the SSS so far posteriorly. ${ }^{28,29,31,34}$ Primary suturing was not believed to be possible due to the width of the opening and the inelasticity of the sinus. Medial extension of the craniotomy with suturing of a dural leaflet over the hole in the SSS and falx was considered, but they were believed to be too hazardous given the risk of significant blood loss during such a maneuver in an $11-\mathrm{kg}$ infant. Direct placement of a temporary stent was not possible because the hole in the sinus was not large enough to accommodate available stents.

It could be argued that the presence of the plate increased the risk of infection, leading to the child's meningitis. However, we believe the long duration of the procedure, the extraordinary blood loss with resultant transfusions, and the prolonged hypotension likely played a pivotal role in the child's infection. . $^{15,17,37}$

\section{Conclusions}

Serious bleeding from an injury to the inferomedial wall of the SSS during hemispherectomy was effectively controlled with a thrombotic plug held in place with a bioresorbable plate. This plate was attached to the outer skull layer and contoured into an S-shape to allow maintenance of compression of a hemostatic plug on the injured inferomedial SSS. The use of the bioresorbable plate proved to be an effective, efficient, and potentially lifesaving technique. This technique may be applicable to other surgical scenarios in which robust cerebral sinus bleeding from poorly accessible locations is encountered, when standard hemostatic techniques prove difficult.

\section{Acknowledgments}

We would like to thank Allyn DiVito for his assistance with the figure annotations. William Nelson, MD, the anesthesiologist caring for this child during surgery, deserves credit for his exem- 
plary resuscitative efforts and for suggesting we use a resorbable plate, which was much easier to contour than our attempts with a metal plate.

\section{References}

1. Basheer SN, Connolly MB, Lautzenhiser A, Sherman EM, Hendson G, Steinbok P: Hemispheric surgery in children with refractory epilepsy: seizure outcome, complications, and adaptive function. Epilepsia 48:133-140, 2007

2. Behera SK, Senapati SB, Mishra SS, Das S: Management of superior sagittal sinus injury encountered in traumatic head injury patients: Analysis of 15 cases. Asian J Neurosurg 10:17-20, 2015

3. Beier AD, Rutka JT: Hemispherectomy: historical review and recent technical advances. Neurosurg Focus 34(6):E11, 2013

4. Bimpis A, Marcus HJ, Wilson MH: Traumatic bifrontal extradural haematoma resulting from superior sagittal sinus injury: case report. JRSM Open 6:2054270415579137, 2015

5. Bower RS, Wirrell EC, Eckel LJ, Wong-Kisiel LC, Nickels $\mathrm{KC}$, Wetjen NM: Repeat resective surgery in complex pediatric refractory epilepsy: lessons learned. J Neurosurg Pediatr 16:94-100, 2015

6. Bulteau C, Otsuki T, Delalande O: Epilepsy surgery for hemispheric syndromes in infants: hemimegalencepahly and hemispheric cortical dysplasia. Brain Dev 35:742-747, 2013

7. Çataltepe O: Hemispherectomy and hemispherotomy techniques in pediatric epilepsy surgery: an overview, in Çataltepe O, Jallo GI (eds): Pediatric Epilepsy Surgery: Preoperative Assessment and Surgical Treatment. New York: Thieme, 2010, pp 205-214

8. de Almeida AN, Marino R Jr, Marie SK, Aguiar PH, Teixeira MJ: Factors of morbidity in hemispherectomies: surgical technique x pathology. Brain Dev 28:215-222, 2006

9. Donaghy RM, Wallman LJ, Flanagan MJ, Numoto M: Sagittal sinus repair. Technical note. J Neurosurg 38:244248, 1973

10. Dorfer C, Ochi A, Snead OC III, Donner E, Holowka S, Widjaja E, et al: Functional hemispherectomy for catastrophic epilepsy in very young infants: technical considerations and complication avoidance. Childs Nerv Syst 31:2103-2109, 2015

11. Galarza M, Gazzeri R: In reply: Tissue-glue-coated collagen sponge (TachoSil) for minor cerebral dural venous sinus laceration: what is the evidence? Neurosurgery 77:E670, 2015 (Letter)

12. Ganau M, Graziano F, Iacopino D: Letter: Advanced hemostatics in the management of cerebral dural sinus lacerations. Neurosurgery 77:E670-E673, 2015 (Letter)

13. Gazzeri R, Galarza M: In reply: Advanced hemostatics in the management of cerebral dural sinus lacerations. Neurosurgery 77:E673-E674, 2015 (Letter)

14. Gazzeri R, Galarza M, Fiore C, Callovini G, Alfieri A: Use of tissue-glue-coated collagen sponge (TachoSil) to repair minor cerebral dural venous sinus lacerations: technical note. Neurosurgery 11 (Suppl 2):32-36, 2015

15. González-Martínez JA, Gupta A, Kotagal P, Lachhwani D, Wyllie E, Lüders HO, et al: Hemispherectomy for catastrophic epilepsy in infants. Epilepsia 46:1518-1525, 2005

16. Gowda S, Salazar F, Bingaman WE, Kotagal P, Lachhwani DL, Gupta A, et al: Surgery for catastrophic epilepsy in infants 6 months of age and younger. J Neurosurg Pediatr 5:603-607, 2010

17. Griessenauer CJ, Salam S, Hendrix P, Patel DM, Tubbs RS, Blount JP, et al: Hemispherectomy for treatment of refractory epilepsy in the pediatric age group: a systematic review. $\mathbf{J}$ Neurosurg Pediatr 15:34-44, 2015
18. Kapp JP, Gielchinsky I, Petty C, McClure C: An internal shunt for use in the reconstruction of dural venous sinuses. Technical note. J Neurosurg 35:351-354, 1971

19. Kestle J, Connolly M, Cochrane D: Pediatric peri-insular hemispherotomy. Pediatr Neurosurg 32:44-47, 2000

20. Kovanda TJ, Rey-Dios R, Travnicek J, Cohen-Gadol AA: Modified periinsular hemispherotomy: operative anatomy and technical nuances. J Neurosurg Pediatr 13:332-338, 2014

21. Lin Y, Harris DA, Curry DJ, Lam S: Trends in outcomes, complications, and hospitalization costs for hemispherectomy in the United States for the years 20002009. Epilepsia 56:139-146, 2015

22. Ma J, Song T, Hu W, Muhumuza ME, Zhao W, Yang S, et al: Reconstruction of the superior sagittal sinus with silicone tubing. Neurosurg Focus 12(6):ecp1, 2002

23. Mazur MD, Neil JA, Agarwal C, Jensen RL, Couldwell WT: Surgical management of a transosseous meningioma with invasion of torcula, superior sagittal sinus, transverse sinus, calvaria, and scalp. Surg Neurol Int 6:40, 2015

24. Oka K, Rhoton AL Jr, Barry M, Rodriguez R: Microsurgical anatomy of the superficial veins of the cerebrum. Neurosurgery 17:711-748, 1985

25. Piastra M, Pietrini D, Caresta E, Chiaretti A, Viola L, Cota F, et al: Hemispherectomy procedures in children: haematological issues. Childs Nerv Syst 20:453-458, 2004

26. Pricola KL, Zou H, Chang SD: Successful repair of a gunshot wound to the head with retained bullet in the torcular herophili. World Neurosurg 76:362.e1-362.e4, 2011

27. Rangel-Castilla L, Hwang SW, Al-Shamy G, Jea A, Curry DJ: The periinsular functional hemispherotomy. Neurosurg Focus 32(3):E7, 2012

28. Rivkin MA, Saraiya PV, Woodrow SI: Sinovenous thrombosis associated with skull fracture in the setting of blunt head trauma. Acta Neurochir (Wien) 156:999-1007, 2014

29. Salunke P, Sodhi HB, Aggarwal A, Ahuja CK, Dhandapani SS, Chhabra R, et al: Is ligation and division of anterior third of superior sagittal sinus really safe? Clin Neurol Neurosurg 115:1998-2002, 2013

30. Sani S, Jobe KW, Byrne RW: Successful repair of an intracranial nail-gun injury involving the parietal region and the superior sagittal sinus. Case report. J Neurosurg 103:567-569, 2005

31. Schaller B, Graf R, Sanada Y, Tolnay M, Rosner G, Wienhard K, et al: Hemodynamic changes after occlusion of the posterior superior sagittal sinus: an experimental PET study in cats. AJNR Am J Neuroradiol 24:1876-1880, 2003

32. Schramm J, Behrens E, Entzian W: Hemispherical deafferentation: an alternative to functional hemispherectomy. Neurosurgery 36:509-516, 1995

33. Sekhar LN, Chanda A, Morita A: The preservation and reconstruction of cerebral veins and sinuses. J Clin Neurosci 9:391-399, 2002

34. Sindou M: Meningiomas invading the sagittal or transverse sinuses, resection with venous reconstruction. J Clin Neurosci 8 (Suppl 1):8-11, 2001

35. Sindou M, Hallacq P: Venous reconstruction in surgery of meningiomas invading the sagittal and transverse sinuses. Skull Base Surg 8:57-64, 1998

36. Spiotta AM, Sivapatham T, Hussain MS, Hui FK, Moskowitz SI, Gupta R: Combined surgical and endovascular approach to a complex dural arteriovenous fistula involving the superior sagittal sinus and torcula. J Stroke Cerebrovasc Dis 21:283-288, 2012

37. Vadera S, Griffith SD, Rosenbaum BP, Seicean A, Kshettry VR, Kelly ML, et al: National trends and in-hospital 
complication rates in more than 1600 hemispherectomies from 1988 to 2010: a Nationwide Inpatient Sample Study. Neurosurgery 77:185-191, 2015

38. Villemure JG, Daniel RT: Peri-insular hemispherotomy in paediatric epilepsy. Childs Nerv Syst 22:967-981, 2006

39. Wilson PJ: Cerebral hemispherectomy for infantile hemiplegia. A report of 50 cases. Brain 93:147-180, 1970

\section{Disclosures}

The authors report no conflict of interest concerning the materials or methods used in this study or the findings specified in this paper.

\section{Author Contributions}

Conception and design: all authors. Acquisition of data: all authors. Analysis and interpretation of data: all authors. Drafting the article: Tuite. Critically revising the article: all authors. Reviewed submitted version of manuscript: all authors. Approved the final version of the manuscript on behalf of all authors: Tuite. Administrative/technical/material support: Tuite. Study supervision: Tuite.

\section{Correspondence}

Gerald Tuite, Division of Pediatric Neurosurgery, Neuroscience Institute, All Children's Hospital/Johns Hopkins Medicine, 601 5th St. S, Ste. 511, St. Petersburg, FL 33701. email: geraldtuite@ gmail.com. 